\title{
El Niño, La Niña, and Climate Resilience in Tanzania
}

\author{
Ephraim Nkonya*, Nicostrato Perez and Jawoo Koo \\ Department of Environment and Production Technology, USA
}

*Corresponding author: Ephraim Nkonya, Department of Environment and Production Technology, International Food Policy Research Institute, USA

Submission: 眥 April 19, 2018; Published: 眥 August 03, 2018

\section{Short Communication}

Shabani Kilama grew up in the remote village of Kibiti, about 88 miles from Tanzania's commercial capital of Dar es Salaam. He watched his mother struggle to feed 13 children, and it was common for the family to skip some daily meals during bad years. Shabani vowed to help his mother live a better life when he grew to adulthood. Immediately after completing high school in 2014, Shabani decided to be an entrepreneur and established a small business selling used clothes and mobile phone calling cards in the Jangwani neighbourhood of Dar es Salaam-an area in the Msimbazi River valley that experiences frequent flash flooding.

Shabani knew of this and planned to move to higher ground when his business became established. He worked 12 hours daily and in only one year, his business grew quickly, allowing him to keep his childhood promise of sending money to his mother. On March 22, 2015, he called her, promising that more was on the way. He went to bed early but was awakened by a heavy downpour. His neighbours came to his door, desperately knocking and telling him to get out quickly as a flash flood was engulfing the whole neigh bourhood. Shaken but composed, Shabani got up and grabbed his phone and bag of sales money-all he could carry in the rush to escape-and ran out in his pajamas. His home and his whole business were washed away down the Msimbazi River, but Shabani was able to save his life. Others were not so fortunate: Five of his neighbours died in the disaster.
Stories like Shabani's are becoming more common in slums in African cities. Between 1993 and 2012, rainfall variability increased by 21 percent compared to the long-term average (19012012). The two phases of the El Niño Southern Oscillation (ENSO)El Niño, a recurring climate pattern driven by warmer-than-normal Pacific Ocean surface temperatures, and La Niña, by cooler surface temperatures-have hit parts of Africa south of the Sahara hard. The strong 2015-2016 El Niño is associated with both severe drought and rainfall events across the region. (ENSO has now entered a "neutral" phase.) Some studies have shown that climate change is likely to intensify ENSO extremes, creating a long-term need to build climate resilience.

In Tanzania, the annual average loss of agricultural production due to drought is about $\$ 200,000$. This average includes years with normal rain but in drought, the cost is much higher. For example, it is estimated that Tanzania's 2007 drought slowed economic growth by 1.1 percent. The El Niño of 2012 was a factor in a drought that led to the deaths of 40 people and the displacement of more than 10,000 people. Drought events impact hydroelectric power, which accounts for 35 percent of Tanzania's supply or electricity. This leads to electrical outages which in turn cause economic losses. The average economic cost of power shortages due to drought is estimated to be over 4 percent of GDP annually.

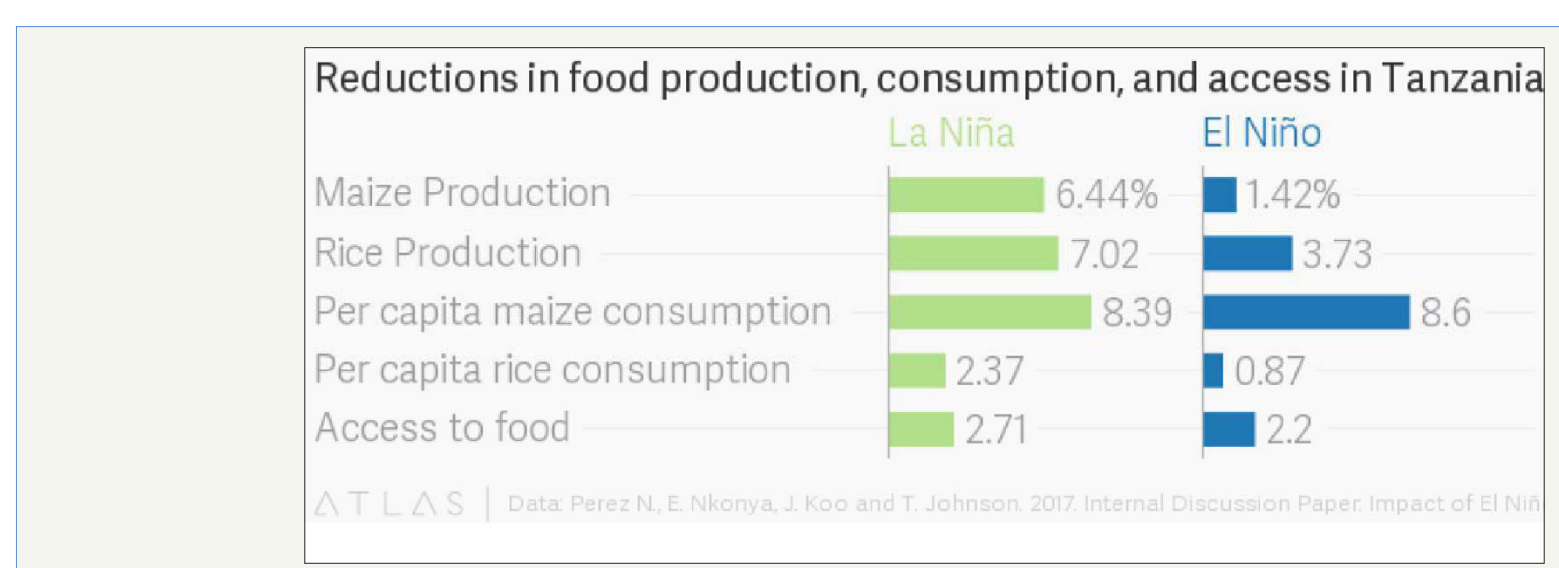

Figure 1. 
Like many countries, Tanzania has designed several policies and strategies for building resilience against drought and flooding. As part of efforts to help the government shape policies, IFPRI has recently studied the impact of El Niño and La Niña. Overall, the La Niña of 2011 and El Niño in 2015 are estimated to have reduced access to food by about 3 percent and 2 percent, respectively (see figure below). In addition, La Niña and El Niño respectively put 1.7 million and 1.5 million people at risk of hunger. La Niña had much larger impact on production than El Niño as it reduced maize and rice production by 6 percent and 7 percent, respectively (Figure 1).
Free trade policies can ease food shortages during climate shocks and can also be a tool for building long-term resilience against climate shocks. Unfortunately, restrictions on cross-border trade have sometimes been the preferred tool to address food shortages. Another IFPRI study showed that such barriers on trade in maize led to a 0.2 percentage point increase in poverty, most severely affecting rural households. Helping farmers adopt climate-smart agriculture (CSA) can also build resilience. Our work shows that adoption of irrigation, integrated soil fertility management and other CSA practices is more likely in areas with high market access and better educated farmers (Figure 2).

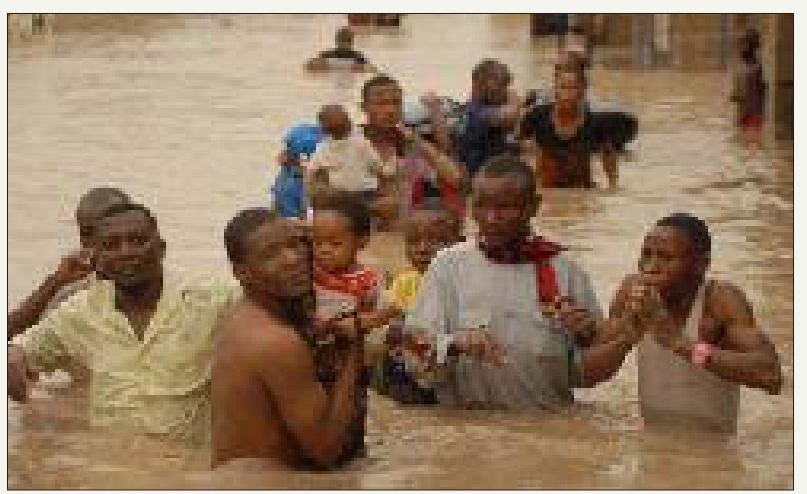

Figure 2.

Finally, focused research and development investments and advisory services on agronomic practices can promote diversification and help enhance soil carbon and soil moisture conserva- tion-increasing maize and rice productivity. Such efforts can go a long way in fostering Tanzania's long-term resilience to climate stresses.
Creative Commons Attribution 4.0 International License

For possible submissions Click Here

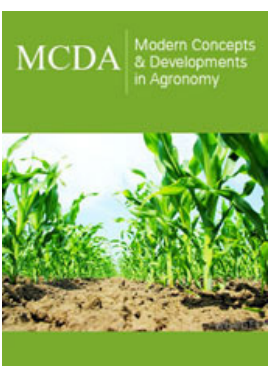

Modern Concepts \& Developments in Agronomy

\section{Benefits of Publishing with us}

- High-level peer review and editorial services

- Freely accessible online immediately upon publication

- Authors retain the copyright to their work

- Licensing it under a Creative Commons license

- Visibility through different online platforms 